\section{ерін}

Epidemiology and Health

\title{
Age-period-cohort analysis of smoking prevalence among young adults in Korea
}

Yong Ho Jee, Sung-il Cho

Graduate School of Public Health, Seoul National University, Seoul, Korea

This article was initially published in the Epidemiology and Health 2016;38:e2016010, with an error in Figure 1C that duplicated Figure 1E.

The authors would like to correct Figure $1 \mathrm{C}$ as below.

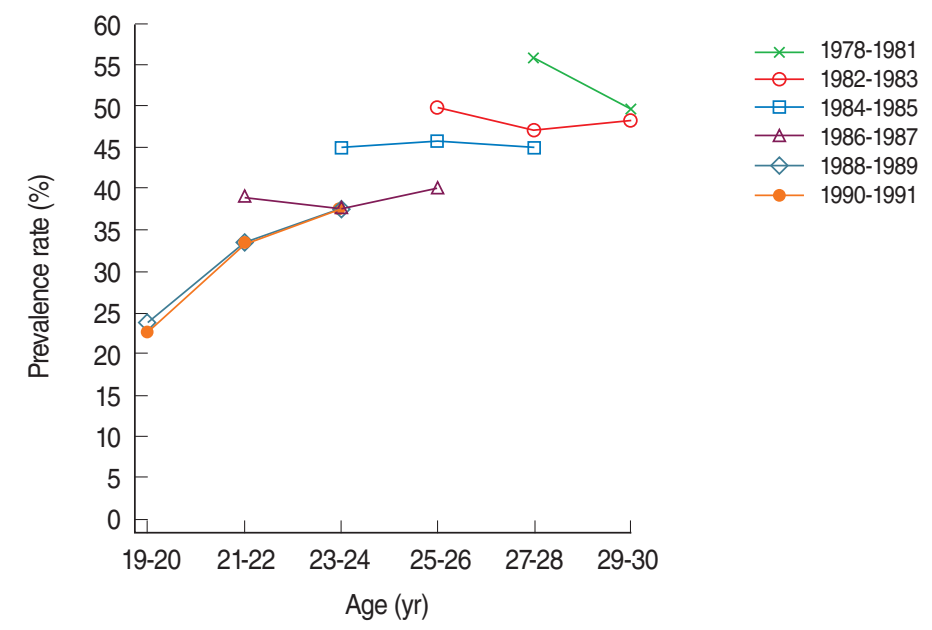

